\title{
Doppler assessment of the fetal circulation in early and late fetal development
}

\author{
Juriy W. Wladimiroff*, Paula van Splunder \\ Department of Obstetrics and Gynaecology, Division of Prenatal Diagnosis, Academic Hospital Rotterdam-Dijkzigt, Erasmus \\ University Rotterdam, Dr. Molewaterplein 40, 3015 GD Rotterdam, The Netherlands
}

\begin{abstract}
With the advent of Doppler ultrasound, fetal cardiac performance has been studied in isolation and in relation to the fetal circulation in general both under physiological and pathophysiological circumstances. In this chapter the central theme is the changes in arterial downstream impedance which occur relative to normal and abnormal fetal development and their association with cardiac and venous flow velocity waveforms. Changes in arterial downstream impedance as expressed by descending aorta and umbilical artery pulsatility index are observed in: (i) normal embryonic/early fetal development; (ii) normal late fetal development associated with behavioural states, and (iii) abnormal late fetal development, in particular fetal growth retardation.
\end{abstract}

Keywords: Doppler ultrasound; Fetal cardiac performance; Fetal development

\section{Normal embryonic/fetal development}

The introduction of transvaginal colour coded and pulsed Doppler system has opened the possibility of studying embryonic/fetal flow velocity waveforms as early as 8 weeks of gestation. Up to 12 weeks, enddiastolic flow velocities are always absent in the fetal descending aorta and umbilical artery reflecting a high fetal and umbilical-placental vascular resistance. End-diastolic flow velocities in these vessels first appear at 13 weeks and are always present as from 15 weeks of gestation [1] (Fig. 1). These dates suggest a change from a high to a low fetal and umbilical placental vascular resistance, which will remain as such during the remainder of pregnancy. Of interest at this point is the trophoblast invasion of the spiral arteries during the early second trimester of pregnancy [2], resulting in low resistance utero-placental vessels. However, the documented reduction in pulsatility index in the fetal descending aorta and umbili-

\footnotetext{
${ }^{*}$ Corresponding author. Tel.: +31104633632 ; fax: $+31 \quad 10$ 4635826 .
}

cal artery may also be determined by the process of placental angiogenesis which takes place at this stage of pregnancy [3].

At cardiac level, biphasic (E-wave, A-wave) atrioventricular flow velocity waveforms can be recorded as early as 9 weeks. Differentiation between transmitral and transtricuspid flow velocities can be made as from 11-12 weeks (Fig. 2). Initially, A-wave velocities are twice those of $\mathrm{E}$-wave velocities, with $\mathrm{E} / \mathrm{A}$ ratio increasing with advancing gestational age. This may suggest a shift of blood flow from late diastole towards early diastole, which may be due to increasing ventricular compliance or raising ventricular relaxation rate [4]. Transtricuspid flow velocities are significantly higher than flow velocities at mitral valve level [5]. Since volume flow is equal to time-averaged velocity multiplied by vessel area, the higher transtricuspid velocities may reflect right ventricular predominance. This is in agreement with observations in normal late pregnancy [6]. Like atrioventricular flow velocities, outflow tract velocities in the ascending aorta, pulmonary artery and ductus arteriosus display a gestational-age related increase. No relationship with downstream impedance has been established. 

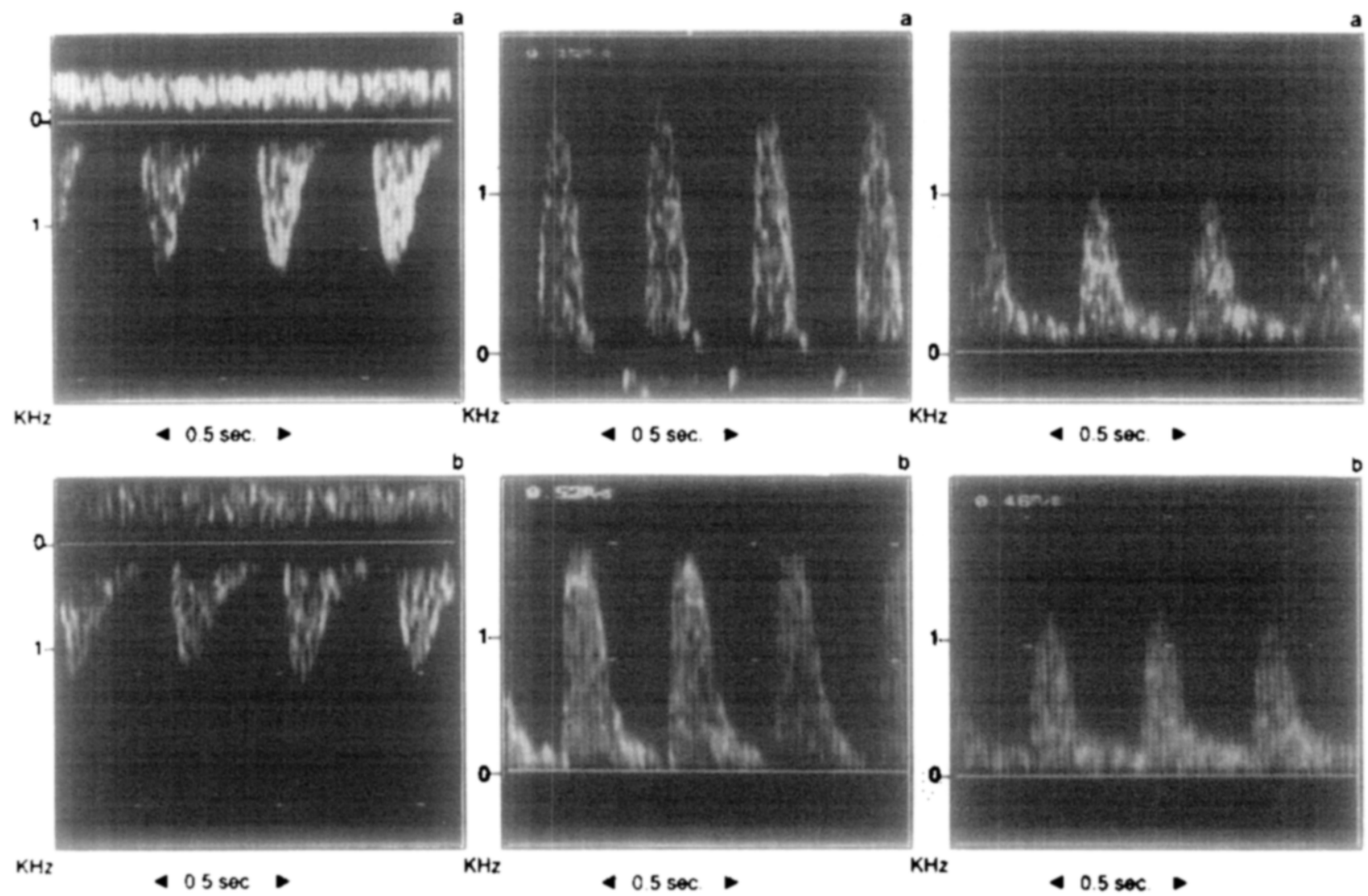

Fig. 1. Maximal flow velocity waveforms from umbilical artery, descending aorta and middle cerebral artery at 11 weeks (left, center, right upper panel) and 13 weeks of gestation (left, center, right lower panel).

On the venous side, pulsations in the umbilical vein may be seen up to 14 weeks of gestation, and may be due to the conductance of cardiac contractions to the umbilical vein as a result of the proximity of the heart. The ductus venosus functions exclusively as a shunt between the umbilical vein and inferior vena cava, allowing the direct flow of well-oxygenated blood towards the foramen ovale and the left heart. Ductus venosus flow velocity waveforms in early pregnancy [7] are very similar to those observed in late pregnancy with a systolic and diastolic forward flow pattern. Pressure gradients across the ductus venosus were

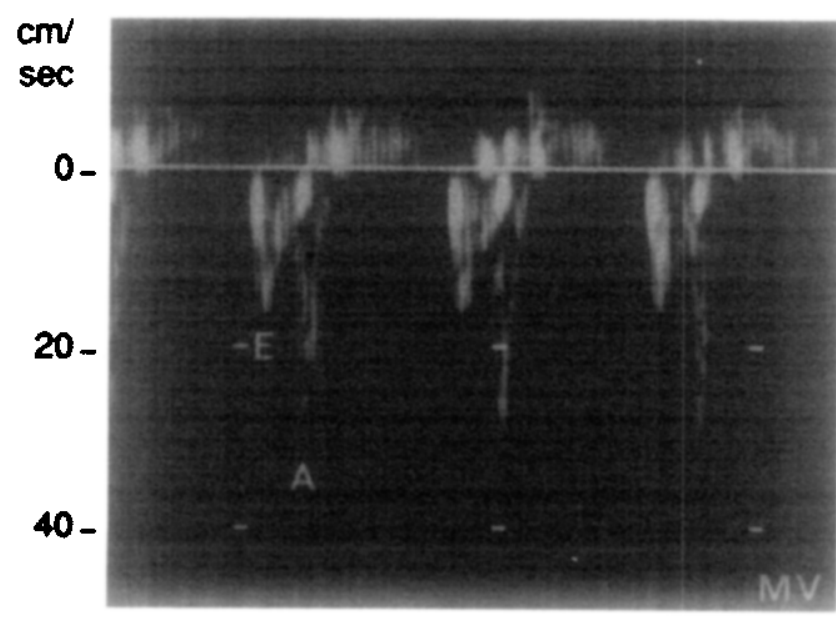

$0.5 \sec$

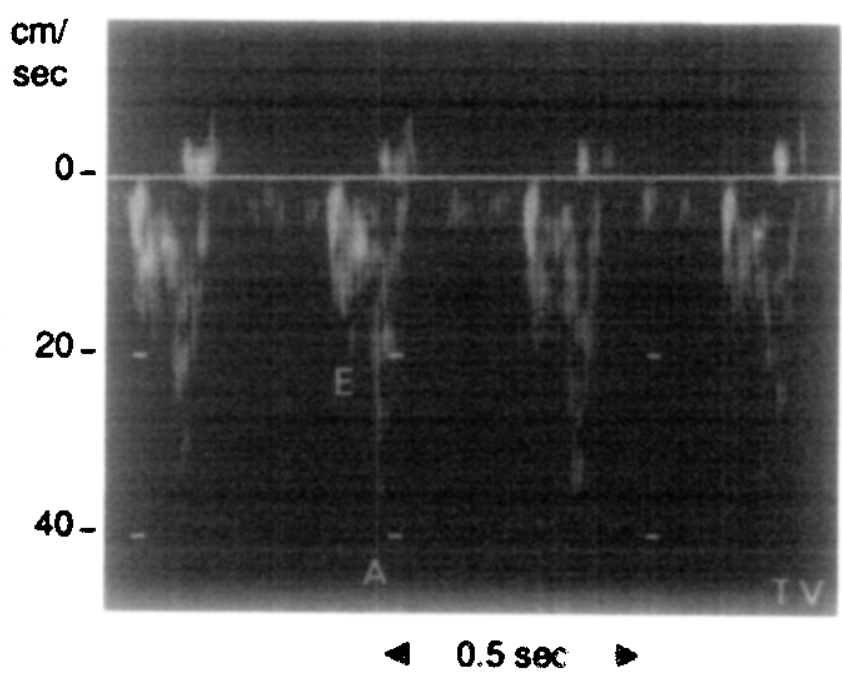

Fig. 2. Transmitral (left) and transtricuspid (right) flow velocity waveforms representing E-wave (early diastolic filling) and A-wave (atrial contraction) components at 12 weeks of gestation. 
estimated using Doppler ultrasonography and the simplified Bernoulli equation. A pressure gradient of 0.1-1.9 $\mathrm{mmHg}$ and $0-0.5 \mathrm{mmHg}$ was calculated during ventricular and atrial contraction, respectively [8]. Also, the inferior vena cava resembles the profile seen in late pregnancy, with a systolic and early diastolic forward component and a late diastolic retrograde component [7]. Percentage reverse flow in this vessel at $11-12$ weeks of gestation is as high as $25-30 \%$, which is approximately six times that seen in late third trimester pregnancies $[7,9]$. This may be due to low cardiac compliance and/or high arterial downstream impedance. This cannot be substantiated as long as volume and pressure measurements are lacking. Rizzo, et al. [10] reported an association between increased reversed flow and umbilical venous pulsations, suggesting a relationship between these waveform characteristics and cardiac filling patterns. Ductus venosus time-averaged velocity is approximately three times the velocity in the umbilical vein and inferior vena cava. This may result in a tendency not to mix, and may thus support the idea of preferential streaming of well-oxygenated blood through the ductus venosus towards the foramen ovale.

\section{Normal late fetal development and behavioural states}

Well-defined behavioural states can be seen in the human fetus from 33-34 weeks of gestation onward. Quiet and active sleep states follow up each other [11]. The quiet sleep state is characterized by occasional body movements, absent eye movements and a stable heart rate pattern with a narrow oscillation bandwidth. The active sleep state comprises frequent and periodic gross body movements, eye movements and a fetal heart rate pattern with a wider oscillation bandwidth than described in the quiet sleep state. Markedly raised end-diastolic velocities resulting in lowered pulsatility index values have been established in the descending aorta during active sleep compared with quiet sleep, suggesting a reduced downstream impedance at fetal trunk and lower extremity level with the objective to increase perfusion of the fetal musculature to meet raised energy demands associated with major activity during this particular behavioural state [12]. A similar pattern exists for the renal arteries [13]. However, this is associated with a lowering instead of an increase in fetal urinary production rates [13]. Surprisingly, no behavioural staterelated changes could be documented in the umbilical artery [14]. Behavioural state dependent changes have also been seen in the intracerebral arteries both for pulsatility index values [14] and absolute flow velocities [15], suggesting increase in cerebral blood flow during active sleep. At cardiac level, a reduced time- averaged velocity at ductus arteriosus level [16] (Fig. 3 ) is associated with a raised time-averaged velocity at the foramen ovale [17] (Fig. 4), suggesting redistribution in left and right ventricular output in favour of the left side of the heart during the active sleep state. The observed increase in blood flow velocity at foramen ovale level is mainly determined by the end-systolic and passive atrial filling phase of the foramen ovale flow velocity waveform, indicating increased passive atrial filling during systole as a result of raised preload. Of interest, therefore, is the observation that in the ductus venosus, peak systolic, peak diastolic and time-averaged velocities are raised by approximately $30 \%$ during active sleep [18]. This suggests augmented volume flow through the ductus venosus during this behavioural state. An increase in volume flow through the ductus venosus during active sleep state would be consistent with the rise in volume flow at foramen ovale [17] and mitral valve level [19] during active sleep. No behavioural state dependent changes were established in the inferior vena cava [20].

\section{Abnormal late fetal development}

An important aspect of prenatal care in late pregnancy is the timely detection of intrauterine growth retardation. Serial fetal biometry, in particular measurements of the upper abdominal circumference will be helpful in establishing fetal growth. A normal utero-placental circulation is necessary to ensure optimal supply of oxygen and nutrients to the developing fetus. In fetal growth retardation as a result of uteroplacental insufficiency, end-diastolic velocities in the descending aorta, renal arteries and umbilical artery may be reduced or even absent reflecting a change from a low arterial downstream impedance to a high arterial downstream impedance at fetal trunk and placental level. Pulsatility index values in these vessels will be raised as a result of this $[21,22]$.

When $P_{\mathrm{O} 2}$ falls below and $P c_{\mathrm{O} 2}$ rises above a certain threshold, aortic and carotid chemoreceptors could be switched on, regulating a vasodilatory response at cerebral arterial level in order to ensure adequate oxygenation to the brain. Thus, fetal growth retardation (hypoxaemia) is associated with a haemodynamic compensatory mechanism which will lead to an increase in blood supply to the brain and a reduction in the perfusion of the gastrointestinal tract, kidneys and lower extremities. Indeed, raised end-diastolic flow velocities occur in intracerebral arteries of growth-retarded fetuses [23]. Time-averaged velocities in the descending aorta plateau at approximately 32 weeks and fall slightly after 40 weeks of gestation unlike time-averaged velocities in the common carotid artery which increase, suggesting that a progressively 

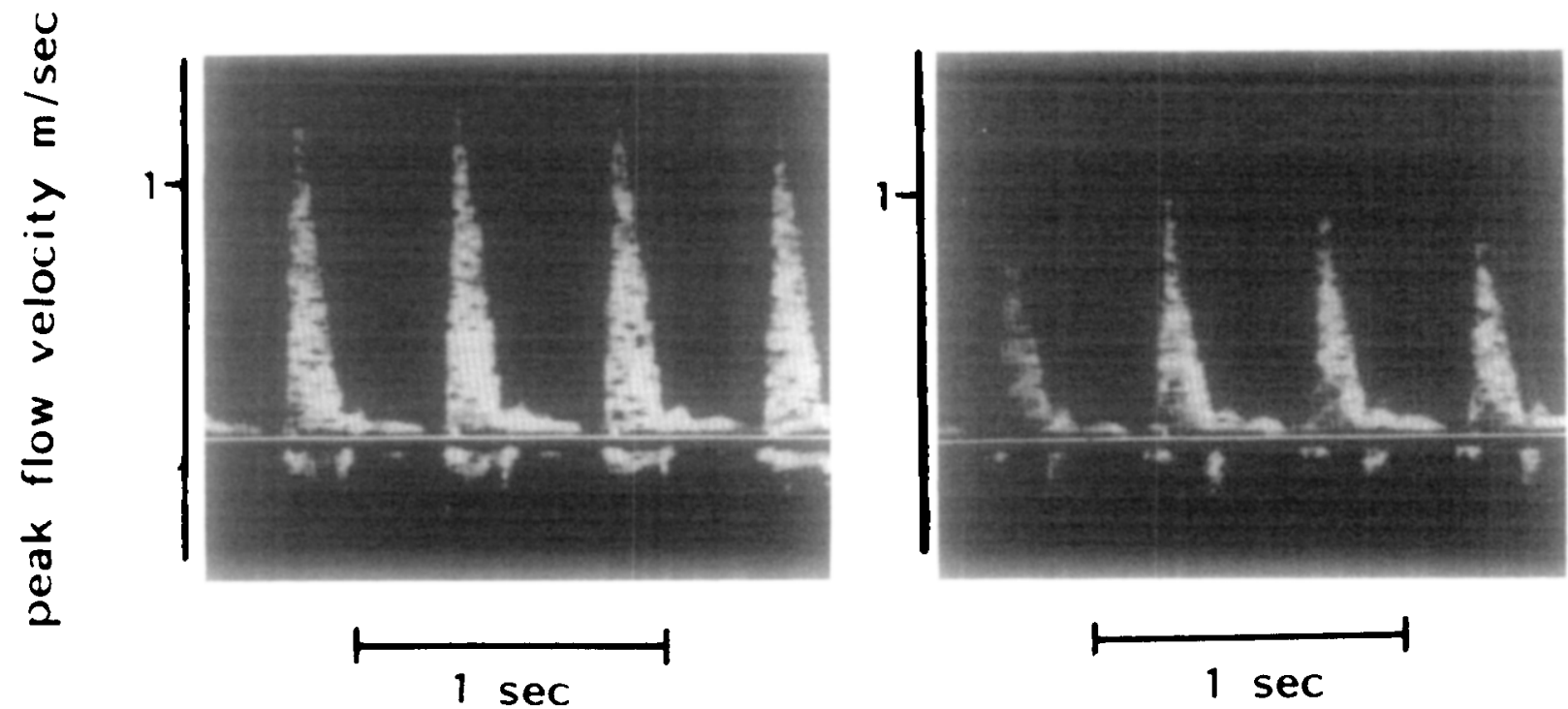

Fig. 3. Maximum flow velocity waveforms from the ductus arteriosus during quiet (left) and active (right) sleep state in the normal growing fetus at 37-38 weeks of gestation (16)

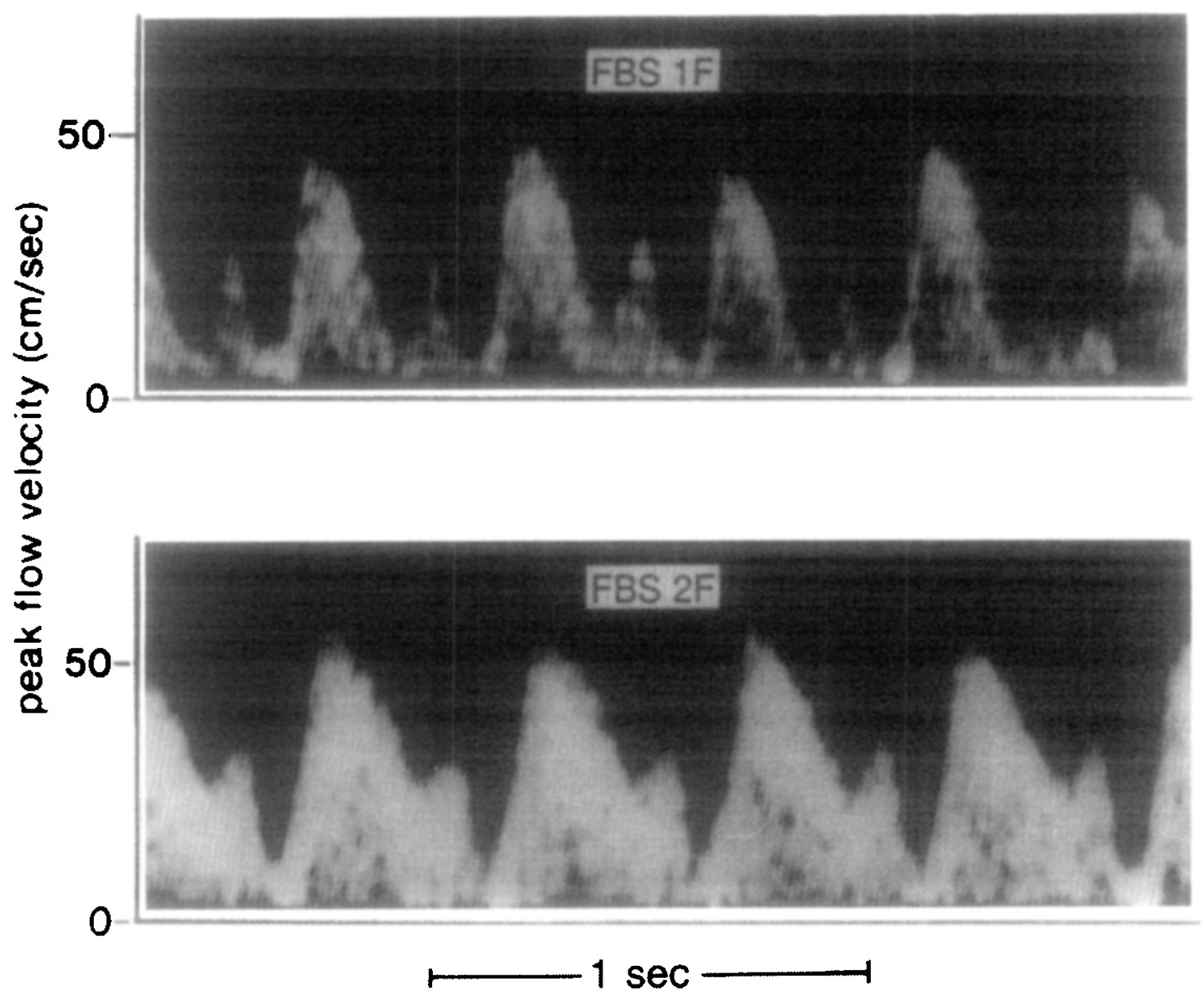

Fig. 4. Maximum flow velocity waveforms at foramen ovale level during quiet (top) and active (bottom) sleep state in the normal growing fetus at 37-38 weeks of gestation (17). 
increasing fraction of the cardiac output is directed to the fetal brain [24].

Haemodynamic adjustment in fetal growth retardation is associated with reduced peak systolic flow velocities in all three cardiac outflow tract vessels [25]. This reduction may be determined by reduced volume flow, increased valve size, reduced cardiac contraction force or increased arterial downstream impedance. Whereas no volume flow or pressure measurements are available, increased arterial downstream impedance may be considered the most likely reason for these reduced outflow tract velocities [25]. The compensatory mechanism(s) of cerebral arterial vasodilatation may be lost when there is severe hypoxaemia, metabolic disturbances or development of brain oedema, resulting in rise in middle cerebral artery pulsatility index [26]. An increase in pulsatility index in severe hypoxaemia may be the consequence of alterations in flow due to reduced cardiac contractility and to a fall in absolute cardiac output [27]. The loss of intracerebral arterial vasodilatation is a critical event since this may be associated with late fetal heart rate decelerations [28]. During the process of haemodynamic adaptation as seen in fetal growth retardation, changes may also be observed in venous return to the heart. Continuous flow patterns in the umbilical vein may become pulsatile. Appearance of late diastolic reverse flow in the ductus venosus and elevated late diastolic reverse flow in the inferior vena cava have been reported in association with fetal growth retardation [29]. A further rise in arterial downstream impedance and ultimately cardiac compromise have been indicted as underlying causes of abnormal venous flow velocity waveform patterns.

\section{Conclusions}

Early fetal development is characterized by a high fetal and umbilical placental vascular resistance. Transition into a low resistance system takes place around 11-12 weeks of gestation, to be maintained during the remainder of pregnancy. An association with placental angiogenesis is suggested. Gestational age-related velocity changes at atrioventricular and outflow tract level do not seem related to arterial downstream impedance. Venous flow velocities display a marked increase with advancing gestational age, in particular in the ductus venosus. Later in pregnancy, behavioural state dependent changes occur in the fetal circulation with the objective to secure optimal blood supply to meet raised energy demands at fetal cerebral and trunk level during the active sleep state. Fetal growth retardation as a result of uteroplacental insufficiency is associated with haemodynamic adjustment triggered by carotid and aortic chemoreceptors depending on the degree of fetal hypoxaemia. Centralization of the fetal circulation with subsequent brain sparing represents the most essential development in haemodynamic adjustment.

\section{References}

[1] Wladimiroff JW, Huisman TWA, Stewart PA. Intracerebral, aortic and umbilical artery flow velocity waveforms in the late first trimester fetus. Am J Obstet Gynecol 1992;166:46-49.

[2] De Wolf F, Peeters C, Brosens I. Ultrastructure of the spiral arteries in the human placental bed at the end of normal pregnancy. Obstet Gynecol 1973;117:833-848.

[3] Jauniaux E, Jurkovic D, Campbell S, Hustin J. Doppler ultrasound features of the developing placental circulation: Correlation with anatomic findings. Am J Obstet Gynecol 1992;166:585-587.

[4] Wladimiroff JW, Huisman TWA, Stewart PA, Stijnen T. Fetal Doppler inferior vena cava, transtricuspid and umbilical artcry flow velocity waveforms in normal late first and early second trimester pregnancies. Am J Obstet Gynecol 1992;166:921-924.

[5] Wladimiroff JW, Huisman TWA, Stewart PA. Fetal cardiac flow velocities in the late first trimester of pregnancy; a transvaginal Doppler study. J Am Coll Cardiol 1991;17:1357-1359.

[6] Reed KL, Meijboom EJ, Sahn DJ, Seagnelli S, Valdez-Cruz LM. Cardiac Doppler flow velocities in human fetuses. Circulation 1986;73:41-46.

[7] Huisman TWA, Stewart PA, Stijnen T, Wladimiroff JW. Flow velocity waveforms in the ductus venosus, umbilical vein and inferior vena cava in normal fetuses at 12-15 weeks of gestation. Ultrasound Med Biol 1993;19:441-445.

[8] Van Splunder IP, Stijnen Th, Wladimiroff JW. Fetal pressure gradient estimations across the ductus venosus in early pregnancy using Doppler ultrasonography. Ultrasound Obstet Gynecol 1995;6:334-339.

[9] Reed KL, Appleton CP, Anderson CF, Shenker L, Sahn DJ. Doppler studies of vena cava flows in human fetuses. Insights into normal and abnormal cardiac physiology. Circulation 1990;81:498-505.

[10] Rizzo G, Arduini D, Romanini C. Umbilical vein pulsations: a physiologic finding in early gestation. Am J Obstet Gynecol 1992;167:675-677.

[11] Nijhuis JG, Prechtl HFR, Martin CB Jr., Bots RSGM. Are there behavioural states in the human fetus? Early Hum Dev 1982;6:177-195.

[12] Van Eyck J, Wladimiroff JW, Noordam MJ, Tonge HM, Prechtl HFR. The blood flow velocity waveform in the fetal descending aorta; its relationship to fetal behavioural states in normal pregnancy at $37-38$ weeks of gestation. Early Hum Dev $1985 ; 12: 137-143$.

[13] De Koekkoek-Doll PK, Stijnen Th, Wladimiroff JW. Behavioural state dependency of renal artery and descending aorta velocimetry and micturition in the normal term fetus. Br J Obstet Gynaecol 1994;101:975-978.

[14] Van Eyck J, Wladimiroff JW, Van den Wijngaard JAGW, Noordam MJ, Prechtl HFR. The blood flow velocity waveform in the fetal internal carotid and umbilical artery; its relationship to fetal behavioural states in normal pregnancy at 37-38 weeks of gestation. $\mathrm{Br} \mathrm{J}$ Obstet Gynaecol 1987;94:736-741

[15] Noordam MJ, Heydanus R, Hop WCJ, Huekstra FME Wladimiroff JW. Doppler colour flow imaging of fetal intra- 
cerebral arteries and umbilical artery in the small for gestational age fetus. Br J Obstet Gynaecol 1994;101:504-508.

[16] Van der Mooren K, Van Eyck J, Wladimiroff JW. Human fetal ductal flow velocity waveforms relative to behavioural states in normal term pregnancy. Am J Obstet Gynecol 1989;160:371-374.

[17] Van Eyck J, Stewart PA, Wladimiroff JW. Human fetal foramen ovale flow velocity waveforms relative to behavioral states in normal term pregnancy. Am J Obstet Gynecol 1990;163:1239-1242.

[18] Huisman TWA, Brezinka $\mathrm{Ch}$, Stewart PA, Stijnen Th, Wladimiroff JW. Ductus venosus flow velocity waveforms relative to fetal behavioural states in normal term pregnancy. Br J Obstet Gynaecol 1994;38:111-119.

[19] Rizzo G, Arduini D, Valensise H, Romanini C. Effects of behavioural states on cardiac output in the healthy human fetus at $36-38$ weeks of gestation. Early Hum Dev 1990;23:109-115.

[21] Trudinger BJ, Giles WB, Cook CM, Bombardier J, Collins L. Fetal umbilical artery flow velocity waveforms and placental resistance: clinical significance. $\mathrm{Br} \mathbf{J}$ Obstet Gynaecol 1985;92:23-30.

[22] Tonge HM, Wladimiroff JW, Noordam MJ, Van Kooten C. Blood flow velocity waveforms in the descending aorta of the human fetus in the third trimester of pregnancy: Comparison between normal and growth-retarded fetuses. Obstet Gynecol $1986 ; 67: 851-855$.
[23] Wladimiroff JW, Van den Wijngaard JAGW, Degani S Noordam MJ, Van Eyck J, Tonge HM. Cerebral and umbilical arterial blood flow velocity waveforms in normal and growth retarded pregnancies. Obstet Gynecol 1987; 69:705-709.

[24] Bilardo CM, Campbell S, Nicolaides KH. Mean blood velocities and flow impedance in the fetal descending thoracic aorta and common carotid artery in normal pregnancy. Early Hum Dev 1988;18:213-221.

[25] Groenenberg IAL, Hop WCJ, Bogers JW, Santema JG, Wladimiroff JW. The predictive value of Doppler flow velocity waveforms in the development of abnormal fetal heart rate traces in intrauterine growth retardation: a longitudinal study. Early Hum Dev 1993;32:151-159.

[26] Bilardo K. Doppler studies of the fetal circulation in hypoxaemic hypoxia and in anaemic hypoxia. Thesis, University of Groningen, 1994.

[27] De Vore GR. Examination of the fetal heart in the fetus with intrauterine growth retardation. Semin Perinatol 1988;12:66-72.

[28] Arduini D, Rizzo G, Romanini C. Changes of pulsatility index from fetal vessels preceding the onset of late decelerations in growth retarded fetuses. Am J Obstet Gynecol 1992;79:605-611.

[29] Arduini D, Rizzo G. Doppler studies of deteriorating growth retarded fetuses. Current Opinion in Obstet Gynecol 1993;5:195-200. 